\title{
Penggunaan Bahan Tekstil sebagai Penguat pada Pembuatan Pipa Apung
}

\author{
Sudirman Habibie*, Mahendra Anggaravidya, Akhmad Amry, Eryanti Kalembang \\ Pusat Teknologi Material, Badan Pengkajian dan Penerapan Teknologi (BPPT) \\ Gedung 224 Puspiptek, Tangerang Selatan, Banten 15314 \\ *Surel: sudirmanhabibie@yahoo.com
}

\section{INFO ARTIKEL}

Diterima 10 Januari 2019

Direvisi 20 Maret 2019

Disetujui 6 Mei 2019

Nomor Artikel 201901

Halaman 1-10

Kata kunci:
Pipa Apung
Pipa Karet
Tekstil
Nylon
Adhesif

Abstract

Rubber hoses or floating pipe are used mainly in oil and dredging industries. For its use, floating pipe may have good elasticity, strength, water proof, oil resistance, hot resistance and bending resistance. However, in its manufacturing, floating pipe needs several good materials, one of them is textile material as reinforcement material that consists of fibres. From this research, nylon fibre can act best as reinforced textile either as single yarn or fabric form for manufacturing hoses. In manufacturing of hose, however, bonding between nylon and rubber is necessary to receive heavy load during operational, therefore it needs adhesive that joint between nylon and rubber. From test result found that floating pipe made by BPPT has fulfilled the standard for oil industry.

Keywords: floating pipe, rubber hose, textile, nylon, adhesive.

\begin{abstract}
Abstrak
Pipa apung banyak digunakan pada industri pengerukan dan industri perminyakan. Dari penggunaannya maka spesifikasi pipa apung harus mempunyai daya lentur (elasticity), kekuatan (strength), tahan air (water proof), tahan minyak (oil resistance), dan tahan panas (hot resistance). Untuk itu pada pembuatannya, pipa apung membutuhkan bahan baku yang baik diantaranya adalah bahan tekstil (kanvas) sebagai penguat yang terdiri dari serat-serat tekstil. Dari hasil penelitian serat nylon mempunyai keunggulan sebagai penguat tekstil baik itu digunakan dalam bentuk benang maupun bentuk kain untuk pembuatan pipa apung. Pada pembuatan hose, bagaimanapun ikatan antara nylon dan karet sangat dibutuhkan untuk menerima beban yang besar, untuk itu dibutuhkan suatu adhesif yang dapat menyatukan antara nylon dan karet. Dari pengujian yang dilakukan dapat disimpulkan bahwa pipa apung buatan BPPT telah memenuhi standard penggunaan pada industri perminyakan.
\end{abstract}

\section{PENDAHULUAN}

Ada lima tipe serat utama yang digunakan sebagai penguat (reinforce) pada produksi barang karet. Katun (cotton) adalah salah satu tipe serat penguat yang masih digunakan pada banyak kebutuhan, tetapi ini secara perlahan telah digantikan oleh serat sintetik, Perlu disebutkan bahwa perbedaan antara USA dan Eropa tentang arti sintetik. Di USA, sintetik diartikan semua serat yang dihasilkan oleh manusia, sehingga viscose rayon diklasifikasikan sebagai serat sintetik.

Di Eropa, "sintetik" digunakan hanya kepada serat yang dibentuk dari polimer yang bukan berasal dari alam. Jadi di Eropa, rayon dengan dasar bahan baku selulosa alam, diklasifikasikan sebagai "man made" atau "artificial" tetapi bukan benang "sintetik". Rayon, adalah serat artificial pertama yang berhasil, yang secara kimia sama dengan katun (cotton) tetapi bermacam proses sampai menjadi serat (benang) memberikan perbedaan sifat-sifat dari katun. Nylon (nylon 6,6 dan Nylon 6) adalah serat sintetik pertama yang digunakan oleh industry karet, dan memperlihatkan beberapa keunggulan dibanding serat selulose (cotton dan rayon). Polyester, dengan kekuatan sama seperti nylon, mempunyai modulus yang lebih tinggi sehingga lebih cocok untuk penggunaan tertentu. Aramid, yang mempunyai sifat kekuatan dan modulus yang tinggi, adalah serat penguat terakhir yang diperkenalkan. Aramid agak terbatas penggunaannya karena harganya mahal walaupun dari kekuatannya aramid sebanding dengan 
kabel baja. Meskipun bukan serat tekstil, serat glass dan baja juga mempunyai banyak penggunaan sebagai penguat pada elastomer (karet), dan sifat-sifat fisik umumnya adalah sebanding dengan tekstil.

Pada tulisan ini akan didiskusikan serat nylon untuk aplikasi bersama karet, aditif kompon karet, serta hasil penelitian dan pengujian pembuatan pipa apung.

\section{STUDI PUSTAKA}

\section{Tipe Serat/Tekstil untuk Pembuatan Hoses}

Pipa apung dari karet telah digunakan cukup lama. Sebelum 1825, pipa apung yang diperkuat dengan 2 lapisan kain katun telah dibuat pada Mandrels dan baja spiral secara bersama untuk menjaga pipa apung pecah pada saat penyedotan atau proses vacuum [1]. Pada akhir 1920an, Barclay Brewery di London, telah mengganti seluruh pipa dari kulit, dengan karet diperkuat dengan cotton walaupun bertentangan dengan perdagangan kulit saat itu. Ini membuktikan keberhasilan sebagai pipa karet (rubber hoses), yang telah mengurangi kebocoran pipa pada tingkat yang diperbolehkan.

Pipa apung (floating pipe) adalah pipa karet yang diperkuat dan dilengkapi dengan bahan pengapung. Floating pipe terdiri dari 3 bagian dasar, yaitu tube bagian dalam, yang berisi medium hose di desain membawa beban, penguat (reinforcement) memberikan kekuatan yang cukup untuk menghadapi tekanan yang dibawa oleh media, dan lapisan luar untuk mencegah komponen lain dari kerusakan karena pemakaian. Untuk kinerja yang baik (performance), seluruh 3 komponen harus menyatu bersama pada saat proses pembuatannya.

Penguat dapat diterapkan baik itu berupa tali (cord) single atau berupa kain tenun (woven fabric). Penguat dipersyaratkan mengalami tekanan operasi termasuk gelombang untuk menjaga pergeseran

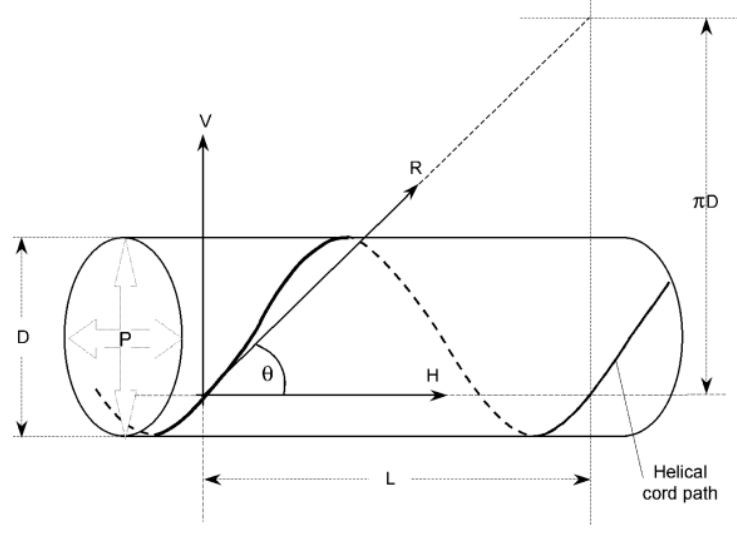

\footnotetext{
$\mathrm{P}=$ Tekanan dalam pipa $\quad \mathrm{D}=$ diameter lilitan kanvas

$\mathrm{R}=$ Tegangan pada kanvas $\mathrm{L}=$ panjang kanvas

$\mathrm{V}=$ Tekanan pada arah memutar $\theta=$ sudut lilitan

$\mathrm{H}=$ Tekanan kearah membujur
}

Gambar 1. Sudut netral awal [1]. (movement) yang tidak semestinya atau pergerakan membengkok dari pipa, serta melindungi terjadinya pecah pada kondisi operasi yang ekstrim.

Dengan penguat tunggal, tali atau kawat diterapkan secara helix, sudut helixnya kritis pada pengontrolan sifat dari pipa karet ketika ada tekanan. Jika sudut helix yang dipilih sekitar $54,75^{\circ}$ (ini mendekati sudut netral, lihat Gambar 1) [1], maka terjadi perubahan minimal pada ukuran hose ketika memperoleh tekanan; jika sudut lebih kecil dari sudut netral diatas maka hose akan cenderung membesar dan lebih kecil dibawa tekanan, ketika sudut lebih besar maka hose akan memanjang. Dengan penguat kain, biasanya kain dipotong miring sehingga pada pembungkusan (wrapping) disekitar inti pipa, sudut benang pada kain akan berada sekitar sudut netral.

Pada Gambar 1 sudut lilitan disebut dengan $\theta$ diterangkan sebagai :

$$
\tan \theta=\pi^{D} / L
$$

dimana tekanan pipa $P$, tekanan kearah membujur pipa disebut $H$ dan tekanan pada arah memutar (radial) disebut $V$. Ketika resultante dari dua tekanan ini, $R$, adalah pada sudut sama dengan sudut lilitan, maka terjadi sudut netral, sehingga : $\tan \theta=V / H$. Dari analisa gaya yang dihasilkan dari tekanan : $H$ $=P \pi(1 / 2 D)^{2}=1 / 4\left(P D^{2} \pi\right)$ dan $V=1 / 2(P D L)$

Jadi untuk $\tan \theta$ sama dengan $V / H \rightarrow$

$$
\begin{aligned}
& \tan \theta=\frac{1 / 2(P D L)}{1 / 4\left(P D^{2} \pi\right)} \quad \rightarrow \text { Pada Gambar } 1, \\
& L=\frac{\pi D}{\tan \theta} \\
& \text { maka } \tan \theta=\frac{2\left(P D^{2} \pi\right)}{P D^{2} \pi \tan \theta} \quad \rightarrow \text { sehingga } \\
& (\tan \theta) 2=2 \text { maka } \theta=54^{\circ} 44^{\prime}
\end{aligned}
$$

Untuk pengukuran sudut lilitan nyata pada pipa, harus dikalkulasi dari ukuran diameter dan puncak panjang dari helix seperti ditunjukan pada perhitungan diatas.

Kain nylon secara luas digunakan untuk tali ban dan pemakaian lainnya, untuk itu ikatan nylon dengan karet sangat penting untuk menerima beban yang besar, sifat-sifat daya guna dan ketahanan lama sebagai ban mobil ditentukan oleh penguat tekstil. Demikian juga yang dialami oleh floating pipe saat pemakaian pada eksplorasi minyak dan pengeboran, sehingga perlu adanya media pemersatu antara kain nylon sebagai penguat dengan karet.

Serat nylon yang banyak digunakan sebagai penguat dengan karet adalah nylon 6 yang terbuat dari polimerisasi caprolactam $\left(\left(\mathrm{CH}_{2}\right)_{5} \mathrm{CONH}\right)$ dan nylon 6,6 yang terbuat dari reaksi polimerisasi hexamethylene diamine $\left(\left(\mathrm{CH}_{2}\right)_{6}\left(\mathrm{NH}_{2}\right)_{2}\right)$ dan asam adipat $\left(\left(\mathrm{CH}_{2}\right)_{4}(\mathrm{COOH})_{2}\right)$, lihat Gambar 2 . 


$$
\begin{aligned}
& \text { Nylon } 6 \underset{\substack{\mathrm{NH} \\
\text { e. caprolactum(6 carbon) }}}{\left.\mathrm{CCH}_{2}\right)_{5}} \rightarrow-\left[\mathrm{NH}^{-}\left(\mathrm{CH}_{2}\right)_{5}-\mathrm{CO}_{-}^{-}\right.
\end{aligned}
$$

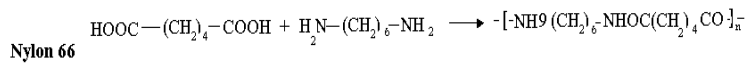

$$
\begin{aligned}
& \text { Adipic acid( } 6 \text { carbon atoms) Hexamethylene diamine }(6 \text { carbons) }
\end{aligned}
$$

Gambar 2. Struktur molekul Nylon 6 dan Nylon 6,6.

\section{Adhesive}

Salah satu masalah penting terjadi selama pembuatan pipa apung yaitu kelemahan ikatan antara bahan tekstil (penguat) dan karet. Untuk mengatasi kekurangan ini, sistim penguat adhesi (adhesionpromoting system), seperti resorcinol-formaldehyde latex dan polysocianates telah lama digunakan untuk membentuk lapisan (coating) pada permukaan tekstil untuk meningkatkan adhesi pada permukaan antarmuka tekstil dan karet. Secara umum lapisan adhesive membentuk lapisan antara tekstil dan karet sehingga ada dua lapisan antarmuka yaitu karetadhesif dan adhesif-tekstil yang terjadi pada satu tempat/lokasi [2]. Peningkatan adhesi tergantung pada kondisi variasi dari perendaman dan karet matrix yang digunakan pada pembuatan.

Pada pembuatan pipa apung (floating pipe), adhesif diperlukan juga sebagai media untuk terjadinya penyatuan antara tekstil dan karet (rubber) serta kawat (wire) pada saat proses pembuatan (manufacturing), sehingga akan menjadi satu kesatuan yang disebut floating pipe.

R. Iyengar [3] melaporkan bahwa adhesi nylon 6,6 dengan karet. Dia meneliti adhesi nylon 6,6 dengan karet alam dengan penekanan penting pada suhu curing yang tinggi dan dalam waktu yang lebih pendek serta peningkatan penggunaan "curing NR" sebagai satu-satunya elastomer dalam pembuatan ban mobil. Studi lainnya dilaporkan adalah adhesi nylon 6,6 dengan chloroprene rubber oleh N.A. Darwish [4]. Tekstil dalam studi ini ditreatmen didalam larutan resorcinol formaldehyde-latex (RFL) konvesional.

Efek dari polusi atmosfir pada suhu tinggi pada adhesi RFL tyre cord dengan karet distudi oleh R.E. Hartz [5]. Efek dari polusi tungku pada suhu tinggi pada adhesi nylon yang telah ditreatment dengan resorcinol-formaldehyde latex dan polyester cord dengan karet diteliti menggunakan uji "hot strip adhesion". Ozon dan ozon UV light ditemukan terjadi lebih besar degradasi dari pada dengan polusi lainnya.

Menurut Wake [6], serat nylon yang direndam lama dalam RFL menunjukan sedikit perubahan karena perlakuan serat nylon dengan resin RFL yang dikerjakan pada suhu tinggi, dapat menyebabkan penetrasi RFL kedalam struktur serat nylon, menyebabkan permukaan serat mengembang mengganggu intramolekular ikatan hydrogen dan melemahkan struktur serat. Walaupun Wootton [7] menyatakan bahwa tidak terjadi reaksi kimia antara RFL dan serat nylon, dia sepakat bahwa beberapa reaksi akan terjadi antara gugus hydroxyl $(\mathrm{OH})$ dan gugus amida (NH) (Gambar 2). Reaksi ini mengganggu struktur molekul dari serat. Sebagai hasilnya serat menjadi kaku, sedikit rapuh dan lebih rentan pecah. Kemungkinan reaksi antara RFL dengan nylon 6,6 dapat dilihat pada Gambar 3 [7].

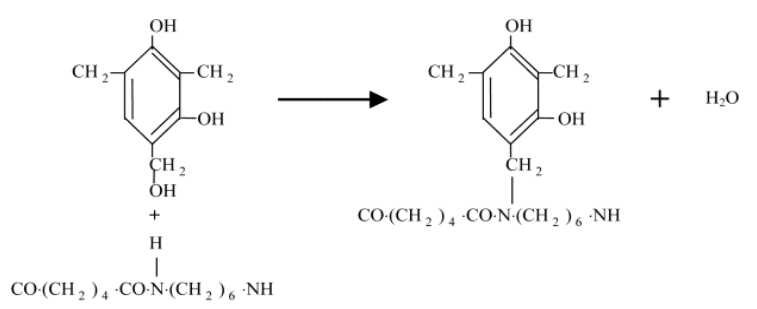

Gambar 3. Kemungkinan reaksi antara RF resin dan nylon 6.6

[7].

Untuk itu dalam pembuatan pipa apung, BPPT memanfaatkan karet alam yang diencerkan menggunakan pelarut (solvent) sehingga memberikan larutan latex karet alam yang mudah penerapannya baik pada karet maupun pada tekstil.

Adhesi berkenaan dengan keadaan dimana dua benda yang berbeda bergabung bersama dengan kontak antarmuka secara baik seperti gaya mekanik atau kerja mekanik dapat ditransfer sepanjang antarmuka. Gaya antarmuka yang mengendalikan dua phasa secara bersamaan mungkin menimbulkan gaya van der Waals, ikatan kimia atau atraksi elektrostatik. Kekuatan mekanik dari sistim ditentukan tidak hanya gaya antarmuka, tetapi juga oleh sifat-sifat mekanik dari zone antarmuka dan dua phasa terbesar. Definisi lain dari adhesi banyak didiskusikan [8,9] tapi tidak ada yang memuaskan. Setiap definisi yang memuaskan harus melibatkan aspek thermodinamika dan mekanik dari adhesi.

\section{Pembuatan Pipa dan Kegunaannya}

Beberapa metode pembuatan pipa karet seperti pelilitan (braiding) dengan benang tunggal dan dibalut secara helix, atau kedua benang tunggal atau dengan kain.

Metode pembuatan pipa karet terutama digunakan untuk proses pengeboran yang kecil sampai sekitar $50 \mathrm{~mm}$ diameter bagian dalam, khususnya untuk aplikasi pada tekanan medium sampai tinggi seperti pipa karet untuk rem mobil. Pada proses ini, pipa bagian dalam diextrude kedalam mandrel yang cocok dan kemudian dilewatkan pada anyaman. Disini, sejumlah serat/benang tunggal diatur dan diputar sekitar tube, pada kutub, untuk memberikan paten anyaman dari penggulungan dan jalinan seperti yang disyaratkan, lihat pada Gambar 4. Tergantung pada ukuran bor dan aplikasinya, lapisan luar karet diekstrude pada anyaman ini. Untuk kekuatan pipa yang lebih tinggi, dapat ditambahkan lapisan kedua anyaman dan lapisan karet berikutnya. 


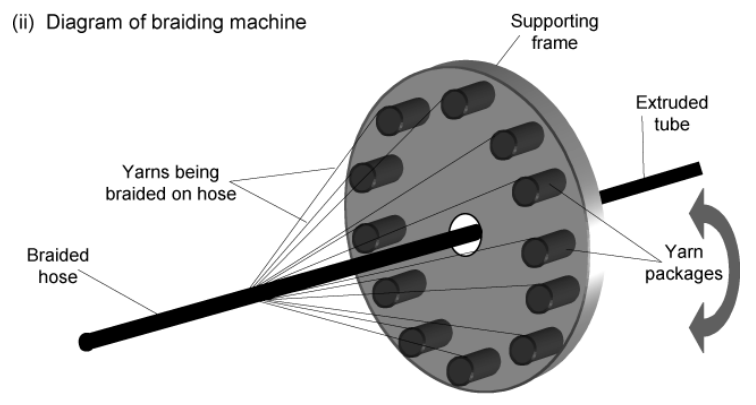

Gambar 4. Cara pembuatan rubber hose ukuran kecil (50 mm) dengan penguat tekstil [1].

Pipa apung untuk penyaluran minyak sampai dengan diameter $60 \mathrm{~cm}$, digunakan untuk mengalirkan minyak dari kapal tanker ke tempat penampungan minyak didarat. Dengan peningkatan ukuran tanker sampai ke super tanker modern, maka tidak dapat lagi digunakan cara-cara konvensional menggunakan kapal angkut kecil tapi dengan cara pipa yang secara kontinu mengalirkan minyak atau liquid. Untuk meningkatkan kinerja pipa karet (hose) pada kondisi tersebut, komponen pelampung dibangun kedalam pipa tersebut sehingga pelampung tambahan tidak lagi diperlukan. Konstruksi dasar tipe pipa ini digambarkan pada Gambar 5. Pipa bagian dalam diperkuat dengan penguat tunggal secara helix, biasanya tali polyester berat atau nylon dan kemudian dibagian luar digulung secara helix dengan kawat baja, untuk mencegah pipa patah disaat vacuum. Di sebelah luar, dipasang busa karet, lonjong pada ujungnya untuk memudahkan pemasangan flange logam yang dipasang pada ujung pipa; lapisan pelampung ini kemudian di balut dengan lapisan tipis karet yang diperkuat dengan kain kanvas, untuk meningkatkan ketahanan putus dan sobek pada lapisan pembalut luar.

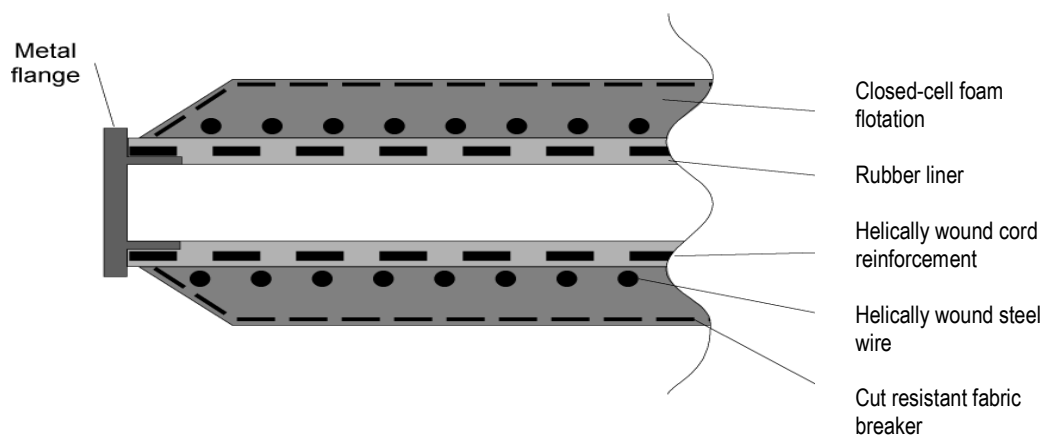

Gambar 5. P ipa penyedot dan pembuang minyak [1].

Penggunaan lain dari tipe pipa ini adalah pada pengerukan (dredging). Dengan ketahanan abrasi khusus pada batas bagian dalam, pipa yang flexible ini dibandingkan menggunakan pipa baja, ini berarti pengeruk mampu mengoperasikan pada laut dalam dari pada menggunakan pipa baja yang kaku.

Tipe pipa kain bundar adalah kain tenun langsung ditenun pada mesin tenun sempit menggunakan teropong. Benang lusi dibagi kedalam 4 (empat) corong (lihat Gambar 6a), dua corong pertama memberikan setengah bagian atas pipa dan dua corong lainnya memberikan setengah bagian bawah pipa, kedua setengah bagian ini dijadikan satu oleh benang pakan, yang mengikat pada setiap ujung dari atas kebawah dan sebaliknya. Ini tentu hanya dapat dicapai dengan mesin tenun menggunakan teropong.

Setelah pertenunan, extruder pipa karet bagian dalam dimasukan kedalam pipa tekstil, ujungnya ditutup dan uap panas (steam) disalurkan kedalam untuk menekan pipa karet bagian dalam kemudian menekan penutup pipa tekstil (woven hose) dan proses ini disebut juga pemanas awetan (cure) karet. Pipa ini khususnya digunakan untuk pemadam kebakaran, karena pipa ini bisa digulung rata setelah digunakan sehingga pipa ini hanya membutuhkan tempat penyimpan yang kecil dari pada pipa yang sama ukurannya untuk pengeboran. Pembuatan pipa diameter kecil ini tidak membutuhkan kawat dan sling baja sebagai penguat, cukup dengan tekstil (kanvas) sebagai penguatnya (Gambar 6b). 


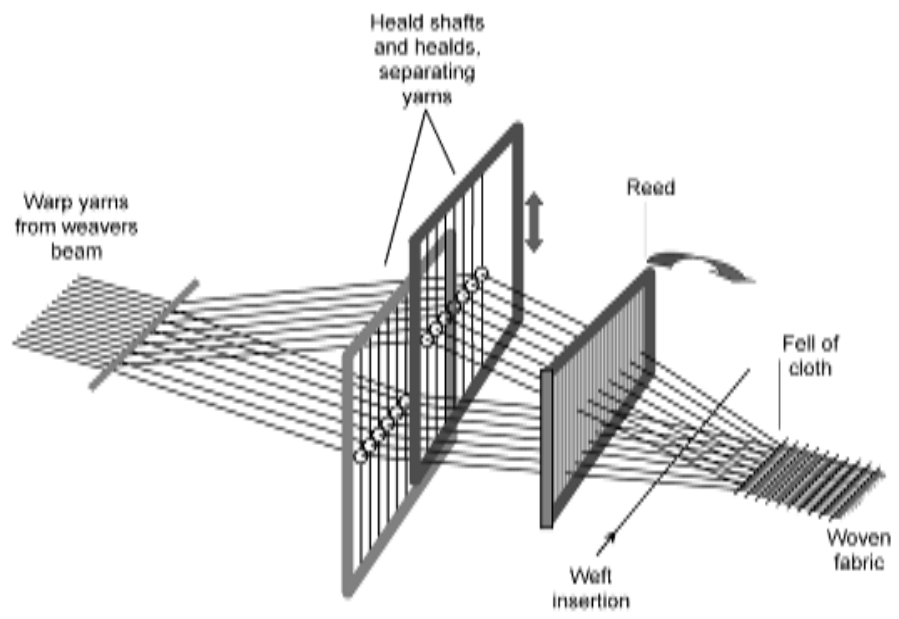

(a)

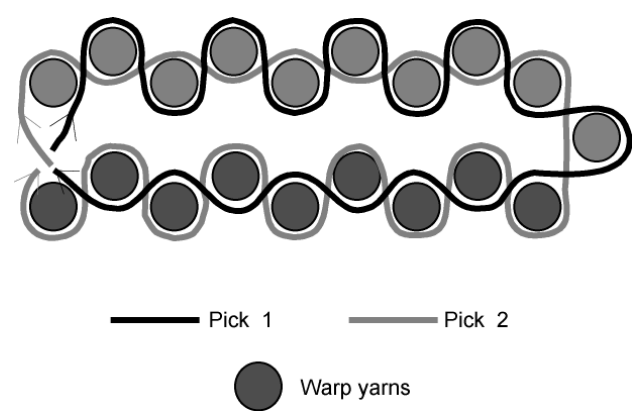

(b)

Gambar 6. (a) Prinsip pertenunan, (b) penampang melintang hasil tenunan [1].

\section{METODE, BAHAN, PROSES PEMBUATAN DAN PENGUJIAN}

\section{Metode}

Metode penelitian yang digunakan adalah menggunakan metode studi pustaka dan penelitian pembuatan pipa apung (floating pipe). Dalam penelitian ini penulis menggunakan data primer hasil penelitian pembuatan pipa apung dan data sekunder sebagai hasil studi pustaka penerapan tekstil dalam industri karet. Data spesifikasi tekstil yang digunakan diusahakan memenuhi standard ISO untuk pembuatan pipa apung. Metode pembuatan pipa apung khususnya penggunaan bahan tekstil akan dapat digunakan sebagai dasar pembuatan pada aplikasi karet lainnya seperti: pembuatan ban menggunakan tyre cord dan balon peluncur kapal (ship airbag), dan lain-lain. Pada penelitian ini lebih difokuskan pada bahan baku penguat kain/kanvas dari serat nylon.

\section{Bahan}

Walaupun pada beberapa industry banyak menggunakan adhesive RFL yang terdapat di pasaran, namun secara teoritis RFL dapat berpengaruh [6] dan bereaksi dengan nylon sehingga menyebabkan permukaan serat mengembang yang mempengaruhi intramolekular ikatan hydrogen dan melemahkan struktur serat, yang menyebabkan nylon menjadi kaku, sedikit rapuh dan lebih rentan pecah.

Oleh sebab itu pada pembuatan pipa apung, BPPT menggunakan adhesive yang dibuat sendiri dengan memanfaatkan karet alam yang diencerkan menggunakan solvent dengan prinsip bahwa perekat (adhesive) yang berasal dari bahan baku sejenis akan lebih mudah berikatan dan berinteraksi. Pembuatan adhesive dilakukan dengan mencampur beberapa bahan seperti kompon karet, toluene (solvent), mixer lem. Untuk adhesive karet bagian luar menggunakan campuran dengan komposisi $1 \mathrm{~kg}$ kompon karet dan 5 liter solvent kemudian diaduk bersama mixer lem selama kurang lebih 4 jam. Sedangkan untuk karet bagian dalam menggunakan solvent jenis methyl ethyl ketone dengan perbandingan $1 \mathrm{~kg}$ kompon karet dan 5 liter solvent diaduk bersama mixer lem selama 4 jam. [10]

Pembuatan adhesive dengan cara memanfaatkan karet alam yang diencerkan diharapkan akan memberi dampak pada hasil ikatan yang lebih baik serta pengurangan adhesive sinthetik lainnya seperti jenis RFL sehingga dapat mengurangi biaya.

\section{Proses Pembuatan Pipa Apung}

\section{Proses Pelilitan}

Proses pelilitan material karet, media pengapung dan material-material penguat lainnya, dilakukan dengan menggunakan alat bantu mesin selang, dimana urutan pelapisan berdasarkan desain konstruksi yang telah dibuat dimana urutan pelapisannya adalah sebagai berikut (lapisan dalam luar) : karet 1 ply (abrasi) : dalam, kanvas 1 ply (no.1 : ki-ka), kawat baja, karet 1 ply, kanvas 1 ply (no.2 : ka-ki), kawat slinge-1, kawat slinge-2, karet 1 ply, kanvas 1 ply (no.3 : ki-ka), karet 1 ply, sponge, kanvas 1 ply (no.4), sponge, kanvas 1 ply (no.5 : kaki), karet 1 ply (ozon) : luar.

\section{Proses Pemasangan Media Pengapung}

Proses pemasangan media pengapung adalah proses dimana lembaran-lembaran media pengapung dipasangkan/dililitkan pada pipa dasar yang telah divulkanisasi awal. Pemasangan media pengapung dilakukan dengan bantuan mesin slang. Apabila diperlukan, untuk menambah kerekatan antara media 
pengapung, setiap 2 lapisan diberi karet bonding dengan lebar $20 \mathrm{~cm}$ dan tebal 1-2 $\mathrm{mm}$ yang dipasang menyudut $45^{\circ}$. Jumlah lapisan media pengapung ditentukan berdasarkan desain konstruksi yang telah dibuat.

\section{Proses Vulkanisasi}

Proses vulkanisasi adalah proses pemberian panas kepada benda yang sedang dibuat, dimana panas yang diberikan berasal dari steam boiler. Untuk pipa dasar vulkanisasi dilakukan dengan tekanan uap 0-1 bar selama 4 jam selanjutnya tekanan dinaikan sampai dengan 2 bar selama 2 jam, sedangkan untuk pipa apung vulkanisasi dilakukan dengan tekanan uap 0-1 bar selama 4 jam selanjutnya tekanan ditahan pada 1 bar selama 3 jam.

\section{Peralatan Uji}

Pengujian dilakukan untuk memenuhi persyaratan menurut OCIMF (Oil Companies International Marine Forum, Guide to Purchasing, Manufacturing and Testing of Loading and Discahrge Hoses for Offshore Moorings, $4^{\mathrm{TH}}$ ED., 1991) yaitu seksi 3.6.1 Minimum Bend Radius, seksi 3.6.2 Hydrostatic Test, dan seksi 3.6.3 Stiffness Test. Peralatan yang digunakan seperti pada table 1 .

Benda uji adalah 3 buah Pipa Apung Submersible Hose, diameter nominal $\varnothing 16$ inci, panjang nominal $10 \mathrm{~m}$, terbuat dari karet yang diperkuat dengan kawat sling baja (steel wire rope), kanvas, dan koil baja heliks, dibuat oleh PT INKABA AGRONESIA, BANDUNG, INDONESIA.

\section{HASIL PEMBAHASAN}

\section{Bahan Tekstil (Kanvas)}

Salah satu tahapan proses pembuatan pipa apung adalah proses pelapisan kain kanvas atau lembaran kain yang telah dilapisi karet. Tahapan ini salah satu tahapan proses yang kritikal karena pada proses ini akan terjadi proses pemanas awetan (curing) dimana akan terjadi proses adhesi maupun reaksi yang akan mempersatukan menjadi satu kesatuan antara tekstil, karet dan kawat dalam bentuk pipa karer (rubber hose).

Pada Gambar 6a dapat dilihat jenis kain yang digunakan adalah kain dari serat nylon dengan anyaman flat. Pada pemakaian testil untuk penguat pada aplikasi karet tertentu menggunakan kepadatan benang berbeda antara lusi (arah panjang kain) dan pakan (arah lebar kain) tergantung kebutuhan pengguna (user). Pada pembuatan pipa apung menggunakan kepadatan (tetal lusi) lebih besar dari pada tetal pakan, lihat table 2 .

Tabel 1. Peralatan uji yang digunakan.

\begin{tabular}{cllc}
\hline No. & \multicolumn{1}{c}{ Equipment } & \multicolumn{1}{c}{ Trademark /Type/Capacity } & Quantity \\
\hline 1 & Measuring Amplifier & HBM, KWS 3073 (1Channel) & 1 units \\
2 & Water-pump & Grundfos, Italy (cap. 25 bar, 250 1/min) & 1 unit \\
3 & Pressure Transducer & Ono Sokki, Japan (cap. 100 bar) & 1 unit \\
4 & Displmnt. Transducer & Ono Sokki, Japan (cap. 500 mm) & 1 unit \\
5 & Measuring Tape & Local made & 1 unit \\
6 & Manometer & (required as monitoring gauge) & 1 unit \\
7 & X-Y recorder & Yokogawa, Japan & 1 unit \\
\hline
\end{tabular}

Sebelum bahan tekstil tersebut digunakan sebagai penguat pada pembuatan pipa apung, maka diperlukan proses awal yakni kain nylon tersebut diproses dengan kompon adhesif. Adhesif ini diperuntukan untuk memberi daya ikat antara kain, karet dan sling baja, sehingga menyatu menjadi satu kesatuan sehingga tidak terjadi slip pada saat operasional pipa apung. Kemudian setelah ditreatment dengan larutan kompon karet cair (kompon karet alam + solvent + mixer lem), maka kain yang telah ditreatment tersebut akan berbentuk lapisan kompon karet pada kain (kanvas) seperti Gambar 7b, sehingga mudah dalam pemakaiannya krn tidak slip dan lebih mudah berinteraksi dengan karet dan kawat seling.
Seperti diterangkan pada Gambar 5, bahwa pada lapisan pertama sebelah dalam setelah lapisan karet maka pada lapisan (ply) berikutnya adalah lapisan penguat tekstil. Lapisan berikutnya adalah lapisan kawat baja agar tidak terjadi penggelembungan pada pipa apung pada saat terjadi tekanan dan tidak terjadi pengempisan pada saat tekanan pipa menurun. Sehingga peran kawat baja untuk menjaga agar ukuran pipa apung tetap stabil pada saat operasional. Lapisan tekstil pada rubber hose tergantung jumlahnya sesuai dengan kebutuhan. Pada pembuatan pipa apung buatan BPPT menggunakan 5 ply khusus untuk pipa apung yang digunakan pada industri perminyakan yang membutuhkan kekuatan tertentu. 


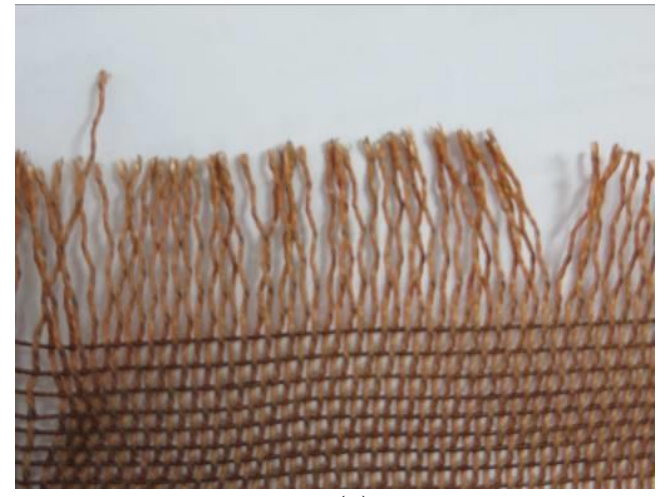

(a)

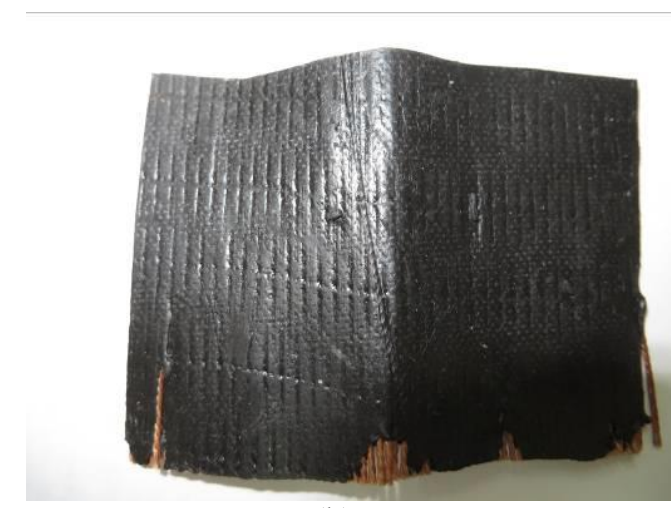

(b)

Gambar 7. Contoh kain tekstil yang digunakan sebagai penguat pada pembuatan pipa apung dengan anyaman flat, (a) kain tekstil awal, (b) setelah diberi adhesif dan dilapisi kompon karet.

Peranan adhesi sangat strategi untuk mengurangi terjadinya perubahan bentuk dari pipa selama operasional karena adanya pergeseran material seperti: kanvas, kawat dan sling yang menyebabkan terjadinya perubahan bentuk yang berdampak pada penurunan mutu pipa apung.

Adhesi berkenaan dengan keadaan dimana dua benda yang berbeda bergabung bersama dengan kontak antarmuka secara baik seperti gaya mekanik atau kerja mekanik dapat ditransfer sepanjang antarmuka. Gaya antarmuka yang mengendalikan dua phasa secara bersamaan mungkin menimbulkan gaya van der Waals, ikatan kimia atau atraksi elektrostatik. Kekuatan mekanik dari sistim ditentukan tidak hanya gaya antarmuka, tetapi juga oleh sifat-sifat mekanik dari zone antarmuka dan dua phasa terbesar. Definisi lain dari adhesi banyak didiskusikan [8] tapi belum ada yang memuaskan. Karena setiap definisi adhesi yang baik harus melibatkan seluruh aspek baik aspek thermodinamika dan mekanik dari adhesi.

\section{Hasil Pengujian Bahan Tekstil}

Pada pembuatan pipa apung, sesuai dengan standard yang ada maka dibutuhkan spesifikasi material yang menjadi panduan dalam pembuatannya secara khusus, untuk itu dalam proses pembuatan pipa apung BPPT bersama pihak industri (INKABA) melakukan beberapa uji spesifikasi material, seperti pada Tabel 2 .

Walaupun tidak betul-betul sama dengan standard, namun spesifikasi material tekstil yang digunakan pada Tabel 2, menunjukan mendekati spesifikasi standard. Hal ini dapat dilihat bahwa jumlah tetal lusi 13 buah per inch, menunjukan tingkat kepadatan benang pada 1 inch kain, dimana semakin kecil tetal lusi harus diimbangi dengan diameter benang yang lebih besar untuk mencapai kekuatan yang diinginkan.

Untuk memperoleh hasil yang optimal pada produk akhir pipa apung maka letak kain tekstil (kanvas) pada pipa harus membentuk sudut netral seperti pada Gambar 1.

Tabel 2. Data hasil pengujian bahan tekstil/kanvas

\begin{tabular}{|c|c|c|c|c|c|c|c|c|c|c|c|c|c|}
\hline \multirow[b]{2}{*}{ No. } & \multirow[b]{2}{*}{$\underset{\text { Uji }}{\text { Parameter }}$} & \multicolumn{12}{|c|}{ Kode Benda Uji } \\
\hline & & 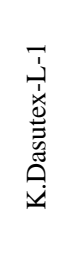 & 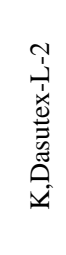 & 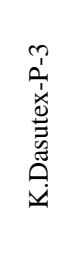 & 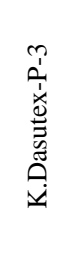 & 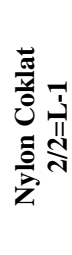 & 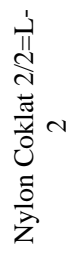 & 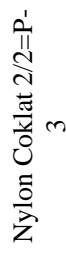 & 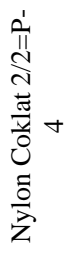 & 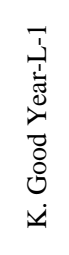 & 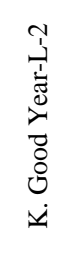 & 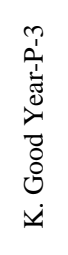 & 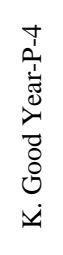 \\
\hline 1. & $\begin{array}{l}\text { Diameter } \\
\text { benang, } \\
\mathrm{mm}\end{array}$ & 0,80 & 0,80 & 0,80 & 0,80 & $\mathbf{0 , 8 0}$ & 0,80 & 0,80 & 0,80 & 0,80 & 0,80 & 0,80 & 0,80 \\
\hline 2. & $\begin{array}{l}\text { Jumlah } \\
\text { benang } \\
\text { arah pakan } \\
\text { per ich, per } \\
\text { buah }\end{array}$ & 24 & 24 & 24 & 24 & 10 & 10 & 10 & 10 & 4 & 4 & 4 & 4 \\
\hline 3. & $\begin{array}{l}\text { Jumlah } \\
\text { benang } \\
\text { arah lusi }\end{array}$ & 32 & 32 & 32 & 32 & 13 & 13 & 13 & 13 & 21 & 21 & 21 & 21 \\
\hline
\end{tabular}




\begin{tabular}{|c|c|c|c|c|c|c|c|c|c|c|c|c|c|}
\hline & $\begin{array}{l}\text { per ich, per } \\
\text { buah }\end{array}$ & & & & & & & & & & & & \\
\hline 4. & Lebar, mm & 78,0 & 71,0 & 71,15 & $\begin{array}{r}71,7 \\
5\end{array}$ & 98,0 & 96,0 & 94,0 & 94,0 & 100,0 & 100,0 & 102,0 & $\begin{array}{r}104, \\
0\end{array}$ \\
\hline 5. & $\begin{array}{l}\text { Gaya Tarik } \\
\text { Maks (P), } \\
\text { kg }\end{array}$ & 235 & 170 & 120 & 125 & 430 & 360 & 190 & 190 & 550 & 530 & 10 & 20 \\
\hline 6. & $\begin{array}{l}\text { Tegangan } \\
\text { Tarik } \\
\text { Maks. (s), } \\
\text { kg/cm }{ }^{2}\end{array}$ & $\begin{array}{r}475, \\
9\end{array}$ & $\begin{array}{r}378, \\
2\end{array}$ & 355,2 & $\begin{array}{r}370, \\
0\end{array}$ & 1706,0 & 1458,0 & 959,4 & $\begin{array}{r}959, \\
4\end{array}$ & 1323,0 & 1275,0 & 123,9 & $\begin{array}{r}243, \\
2\end{array}$ \\
\hline 7. & $\begin{array}{l}\text { Kekuatan } \\
\text { Sobek } \\
\text { pertama } \\
\text { (trafesium), } \\
\text { kg }\end{array}$ & 148 & 100 & 118,3 & 115 & 210 & 190 & 130 & 130 & 387 & 464 & 4,3 & 10,3 \\
\hline
\end{tabular}

\section{Hasil Pengujian Produk Pipa Apung}

\section{Uji Hidrostatik}

Masing-masing pipa harus diuji dengan air bertekanan sampai dengan tekanan kerjanya. Kemudian tekanan direkam/dicatat.

Hasil uji menunjukkan bahwa tidak terdapat kebocoran pada pipa apung No. FP-228-001-07 dan No. FP-228-002-07. Selain itu, kedua pipa tersebut tidak mengalami puntiran/twist selama pengujian berlangsung. Selain itu dari hasil uji tarik menunjukan tidak terjadi perubahan ukuran selama pengujian pada kedua contoh pipa apung, lihat table 3.

Seperti diketahui serat nylon mempunyai sifat elastisitas $100 \%$ pada penarikan kearah panjang sampai $8 \%$ dan melting point pada temperature $263^{\circ} \mathrm{C}$ [11], sehingga pada pipa apung dengan komposisi kain kanvas kombinasi 4 (ply)(empat lapis kanvas) serta adanya paduan kekuatan kawat baja maka memberikan kekuatan akhir pipa apung yang diinginkan. Seperti pada Gambar 7 diuji dengan air bertekanan memberikan stabilitas pada dimensi pipa pada tekanan rendah dan akan terjadi perubahan dimensi pada tekanan lebih tinggi.

Tabel 3. Hasil uji hidrostatik pipa apung No. FP-228-001-07 dan No. FP-228-002-07

\begin{tabular}{|l|l|l|l|}
\hline \multirow{2}{*}{ No. } & \multicolumn{1}{|c|}{ Besaran terukur } & \multicolumn{2}{|c|}{ Pipa } \\
\cline { 3 - 4 } & & No. FP-228-001-07 & No. FP-228-002-07 \\
\hline 1 & Panjang asal (0.7 bar) & $10.780 \mathrm{~m}$ & $10.770 \mathrm{~m}$ \\
\hline 2 & Panjang pada 15 bar & $10.755 \mathrm{~m}$ & $10.920 \mathrm{~m}$ \\
\hline 3 & Panjang pada 0.7 bar terakhir & $10.778 \mathrm{~m}$ & $10.770 \mathrm{~m}$ \\
\hline 4 & Temporary elongation & $(10.755-10.780) / 10.78=-$ & $(10.92-10.77) / 10.77=$ \\
& & $0.0023=-0.23 \%$ & $0.0139=1.39 \%$ \\
\hline 5 & Permanent elongation & $(10.778-10.780) / 10.78=-$ & $\begin{array}{l}(10.77-10.77) / 10.77=0 \\
=0 \%\end{array}$ \\
\hline
\end{tabular}

Grafik tekanan dan perubahan panjang pipa terhadap waktu diperlihatkan pada Gambar 8.

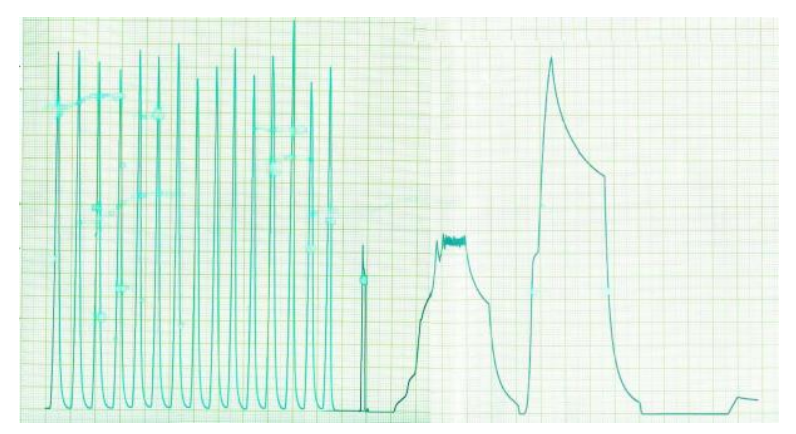

Gambar 8. Hasil Pengujian Prototipe Floating Hoses (10 m; 4 ply)

\section{Uji Minimum Bend Radius}

Tujuan dari pengujian ini adalah untuk memastikan bahwa pipa tersebut dapat ditekuk (bend) sampai dengan radius tekuk minimum (minimum bend radius), yaitu 6 kali diameter nominal pipa, tanpa mengalami kerusakan, permanent ovalling, atau deformasi tetap [12].

Dari hasil pengamatan secara visual setelah uji tekuk (bending test), ketika pipa dikembalikan dalam posisi lurus setelah diuji tekuk ternyata tidak ada deformasi permanent pada pipa, misalnya lekukan permanent atau ovalling (penampang pipa menjadi oval, bukan lagi lingkaran). Hal ini menunjukan bahwa bending test terhadap 2 pipa apung ini tidak terjadi perubahan permanen pada bentuk dan performance pipa apung. 


\section{Perhitungan Kekakuan rata-rata Pipa Apung}

$\mathrm{L}=$ Panjang pipa $=10.78 \mathrm{~m}$

$\mathrm{A}=$ Panjang batang moment $=1.83 \mathrm{~m}$

$\mathrm{Z}=$ Sudut antara sistem tarik dan batang moment $=118^{\circ}$ $\sin 118^{\circ}=0.88947$

\begin{tabular}{|c|c|c|c|c|}
\hline No. & $\begin{array}{c}\text { Moment } \\
\text { Tension (N) }\end{array}$ & $\begin{array}{c}\text { Balance } \\
\text { Tension (N) }\end{array}$ & $\begin{array}{c}\text { Defleksi pipa } \\
\mathrm{H}(\mathrm{m})\end{array}$ & $\begin{array}{c}\text { Kekakuan, EI } \\
\left(\mathrm{Nm}^{2}\right)\end{array}$ \\
\hline 1 & 1350 & 1340 & 0.71 & 39004.99 \\
2 & 1010 & 1060 & 0.86 & 2409171 \\
3 & 1100 & 1150 & 0.625 & 36104.17 \\
4 & 1590 & 1580 & 0.54 & 60401.55 \\
5 & 1300 & 1350 & 0.61 & 43717.8 \\
\hline
\end{tabular}

Harga Rata-Rata:

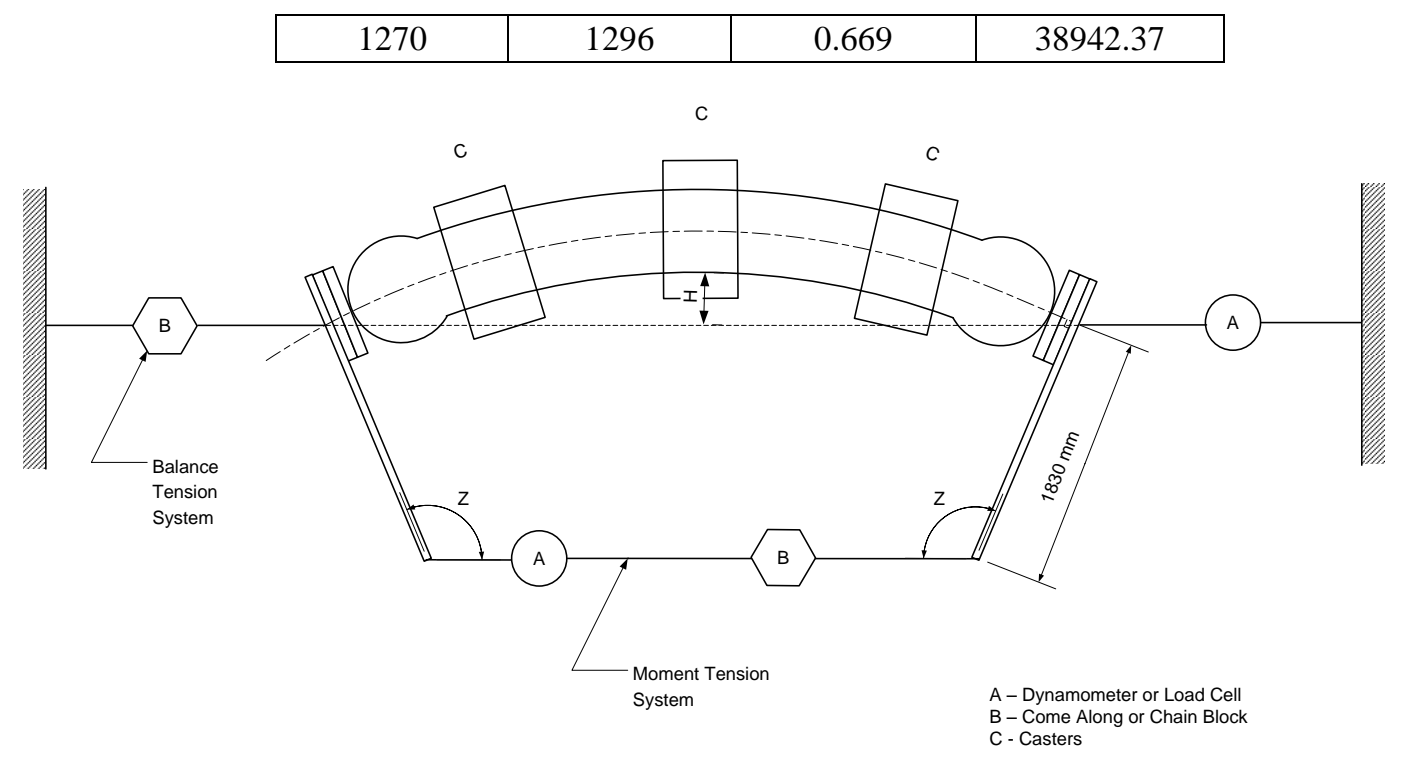

Gambar 9. Skema set-up pengujian kekakuan pipa apung (stiffness test).

\section{Uji Stiffness/Kekakuan Pipa}

Salah satu bentuk pengujian yang dilakukan pada pipa apung adalah uji kekakuan (stiffness). Tujuan dari pengujian ini adalah untuk menentukan kekakuan pada tekukan (bending stiffness), yaitu besarnya harga EI dari pipa apung pada radius tekukan sama dengan panjang pipa. Skematik system pengujian adalah seperti terlihat pada Gambar 9, dimana pipa apung diuji dalam keadaan kosong dan tanpa tekanan internal $[13,14]$.

\section{KESIMPULAN}

Pada pembuatan barang industri yang terbuat dari karet seperti: pipa bor, pipa pemadam kebakaran, ban mobil, pipa apung, balon peluncur kapal, dan produk karet lainnya dibutuhkan penguat untuk meningkatkan performance dari barang karet tersebut. Material penguat terdiri dari sling, kawat baja dan kanvas (kain tekstil dari serat nylon).

Pipa apung dengan ukuran diameter lebih dari $60 \mathrm{~cm}$, banyak digunakan untuk industri pengerukan dan industri perminyakan. Dari penggunaannya maka spesifikasi pipa apung harus mempunyai daya lentur (elasticity), kekuatan (strength), tahan air (water proof), tahan minyak (oil resistance), dan tahan panas (hot resistance). Ada pipa apung yang 
menggunakan kombinasi dari penguat tekstil dan sling serta kawat baja, dan ada pula pipa apung yang menggunakan hanya penguat tekstil (kanvas) saja tergantung pengguna. Sedangkan untuk pipa karet ukuran kecil diameter kurang dari $10 \mathrm{~cm}$ seperti: pipa untuk pemadam kebakaran, pipa rem mobil dan lainlain, cukup menggunakan penguat tekstil pada pembuatannya.

Pembuatan pipa apung memerlukan adhesive yang berperan sebagai media penghubung antar muka antara tekstil dengan karet. Banyak jenis adhesive yang dapat digunakan dalam proses ini, namun pada pembuatan pipa apung, BPPT menggunakan adhesive yang dirancang menggunakan karet alam yang dicairkan dalam solvent dengan prinsip bahwa adhesive yang berasal dari bahan dasar berasal dari polimer sejenis akan lebih kuat berinteraksi.

Hasil pengujian hidrostatik, bending test dan stiffnes test, pipa apung buatan BPPT menunjukan performance yang baik sesuai dengan standard yang ada.

\section{UCAPAN TERIMA KASIH}

Ucapan terima kasih disampaikan kepada Kementerian Riset dan Teknologi atas terselenggaranya Program SiNas ini, demikian juga disampaikan kepada Direktur Pusat Teknologi Industri Proses BPP Teknologi, dan terakhir secara khusus kepada Kepala Divisi INKABA PT Agronesia Bandung yang telah membantu kelancaran penelitian ini.

\section{DAFTAR PUSTAKA}

[1] Wootton, D.B. The Application of Textile in Rubber. RAPRA Technology LTD, Shawbury, Shrewsbury. UK. 1998.

[2] Lechtenboehmer, A., Moneypenny, H.G. and Mersch, F. Br. Polym. J. Vol. 22. pp. 265 (1990).

[3] Iyengar, R., Rubb. World. Vol. 208. No.1. pp. 31-45. (1993).

[4] Darwish, N.A., Muanyag es Gummi. Vol. 30. No. 10. pp. 246-248. 1993.

[5] Hartz, R.E. and Adams, H.T., J. Appl. Polym. Sci. Vol. 21. No.2. pp. 525-533. 1977.

[6] Wake, W.C. Adhesion and Formulation of Adhesives. Applied Science Publishers. London. 1976.

[7] Wootton, D.B. Textile Reinforcement of Elastomers. Applied Science Publishers Ltd, London and New Jersey. 1982.

[8] K. L. Mittal Polymer Eng. SCi., Vol. 17. pp. 467. 1977.

[9] ASTM D 907. Standard Definitions of terms Relating to Adhesives. Annual Book of ASTM Standards. Vol. 22. pp. 233. 1977.
[10] Laporan akhir Pembuatan Pipa Apung. PTIPBPPT. 2008.

[11] I. Kim, E. Kono, and T. Takagishi. Textile Research Journal. No. 66. pp. 763-770. 1996.

[12] SNI ISO 37: 2010. Karet, Vulkanisat atau Termoplastik - Penentuan Sifat-Sifat TeganganRegangan.

[13] ASTM D2240 - 05, Standard Test Method for Rubber Property - Durometer Hardness. 2010

[14] Laporan Hasil Uji: Bend Radius, Stiffness, Hidrostatic Pipa Apung $\emptyset 16$ inch. B2TKS BPPT. 2008. 